\title{
In-vitro Whitening Efficacy of High Cleaning Silica and Tetrasodium Pyrophosphate Containing Dentifrice
}

\author{
Jieun Yang, Kyotae Moon, Kyunghee Oh, Wonho Ha
}

$L G H \& H$ Research Center, Seoul, Korea

Objectives: Whitening efficacy of tooth surface could be achieved by physical and chemical action. High cleaning silica (HCS) and tetrasodium pyrophosphate (TSPP) efficiently removed tooth stain via physical and chemical manner, respectively. The aim of this study is to evaluate the stain removal efficacy of HCS and TSPP containing dentifrice.

Methods: In-vitro stain removal evaluations were done by Modified Stookey's methods. Preparation of stained hydroxyapatite (HA) specimens; HA powder blended with polyvinyl alcohol was compressed and sintered at $1000{ }^{\circ} \mathrm{C}$. HA disks were stained using a broth consisted of coffee, tea and mucin solution in sterile trypticase soy broth, and then allocated to each group ( $\mathrm{n}=8$ per group): Control group: a dentifrice containing silica $20 \%$ (abrasive silica 13\%) and sodium fluoride $0.22 \%$, Experimental group: a dentifrice containing silica $20 \%$ (HCS $13 \%$ ), sodium fluoride $0.22 \%$ and TSPP $3.4 \%$. The dentifrices were tested as a slurry consisting of $25 \mathrm{~g}$ of dentifrice mixed with $40 \mathrm{~mL}$ of deionized water, and the HA specimens were brushed for 5400 strokes. $\mathrm{L}^{*}, \mathrm{a}^{*}$, b* values of HA specimen were measured at before and after brushing using colorimeter (CR-321, Minolta Camera Co., Osaka, Japan). Color change of specimen was calculated and then analyzed by paired t-test.

Results: The color change ( $\triangle \mathrm{E}$ ) after brushing was significantly different between two groups ( $\mathrm{p}<0.001)$. The mean $\Delta \mathrm{E}$ value of control group was $5.18 \pm 1.72$ and experimental group was $20.05 \pm 1.13$. Experimental group showed 3.87 times higher whitening efficacy than control group.

Conclusions: The dentifrice including HCS and TSPP showed significantly increased whitening efficacy compared to control dentifrice. It means the dentifrice containing HCS and TSPP makes teeth appear whiter by removing extrinsic stains via physical and chemical manner.

Keywords: High cleaning silica, Tetrasodium pyrophosphate, Whitening, Stain removal

Copyright (C) 2021. Korean Academy of Preventive Dentistry. All rights reserved.

This is an Open Access article distributed under the terms of the Creative Commons Attribution Non-Commercial License (http://creativecommons.org/licenses/ by-nc/4.0) which permits unrestricted non-commercial use, distribution, and reproduction in any medium, provided the original work is properly cited. 